\title{
Research Paper: The Relationship Between Job Satisfaction and Crisis-related Factors in Rehabilitation Staff Regarding the Prevention Approach
}

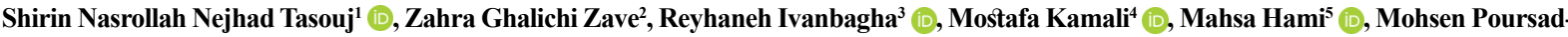
eqiyan $^{6,7}$, Seyed Habibollah Kavari ${ }^{8 *}$ []

1. Shohada-e-Haftom-e-Tir Hospital, Iran University of Medical Sciences, Iran, Iran.

2. Health Sciences Research Center, Torbat Heydariyeh University of Medical Sciences, Torbat Heydariveh, Iran

3. Department of Midwife, School of Nursing, Khalkhal University of Medical Sciences, Khalkhal, Iran.

4. Department of Health Information Technology, Torbat Heydariyeh University of Medical Sciences, Torbat Heydariyeh, Iran.

5. Health Management and Economics Research Center, Health Management Research Institute, Iran University of Medical Sciences, Tehran, Iran

6. Social Determinants of Health Research Center, Ardabil University of Medical Sciences, Ardabil, Iran.

7. Department of Occupational Health Engineering, School of Health, Ardabil University of Medical Sciences, Ardabil, Iran

8. Department of Rehabilitation Management, University of Social Welfare and Rehabilitation Sciences, Tehran, Iran.

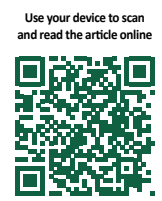

Citation: Nasrollah Nejhad Tasouj Sh, Ghalichi Zave Z, Ivanbagha R, Kamali M, Hami M, Poursadeqiyan M, et al. The Relationship Between Job Satisfaction and Crisis-related Factors in Rehabilitation Staff Regarding the Prevention Approach. Health in Emergencies and Disasters Quarterly. 2021; 6(2):89-98. http://dx.doi.org/10.32598/hdq.6.2.189.12

\section{(i) (3)}

Article info:

Received: 30 Aug 2020

Accepted: 10 Oct 2020

Available Online: 01 Jan 2021

\section{A B STRACT}

Background: Job satisfaction is one of the most critical and influential parameters to increase the productivity and efficiency of any organization. Crisis management during disasters is one of the most influential factors, and because disasters put pressure on health care systems, all medical staff, including those working in Rehabilitation, must have the necessary experience and skills to manage in an emergency. Therefore, this study aimed to investigate the relationship between job satisfaction and crisis-related factors in the staff of non-governmental rehabilitation centers under the supervision of the Tehran Welfare Organization with a preventive approach.

Materials and Methods: The present study is a descriptive-correlational study, in which 1403 people from 28 rehabilitation centers in Tehran Province in 2018 were surveyed and selected by the census. We used the data recorded in the demographic section of the standard Employee Satisfaction Survey. This questionnaire consists of 39 items and 5 subscales to measure job status (10 questions), supervisor (8 questions), coworkers (10 questions), promotion (5 questions), and payment (6 questions). It included components of job activity, management, group activities, incentive system, and payment system. The study demographic characteristics were age, gender, level of education, work experience, and the number of working hours. Besides, a researcher-made questionnaire was used to assess the relationship between general safety status and firefighting as a criterion for crisis management and job satisfaction. In different cases, different tests were used. Finally, the data were analyzed using SPSS v. 20.

Results: In this study, 657 (46.8\%) men and 746 (53.2\%) women participated. Findings showed that the average job satisfaction of employees was 3.12 , which was at a moderate

Disaster, Preparedness,

Occupational heath

* Corresponding Author:

Seyed Habibollah Kavari, PhD.

Address: Department of Rehabilitation Management, University of Social

Welfare and Rehabilitation Sciences, Tehran, Iran.

E-mail:h.kavari@uswrac.ir
* Corresponding Author:

Mohsen Poursadeqiyan, PhD.

Address: Social Determinants of Health Research Center, Ardabil University of Medical Sciences, Ardabil, Iran.

E-mail: poursadeghiyan@gmail.com 
to high level (maximum score in each department was 5). There was no significant relationship between demographic information (such as age, work experience, level of education, and the number of working hours) and job satisfaction. However, there was a significant relationship between gender and job satisfaction, so that men had higher job satisfaction than women. Also, there was a significant relationship between public safety and firefighting and job satisfaction, so that an increase in the score of general safety and firefighting as an indicator of crisis management led to a significant increase in job satisfaction.

Conclusion: According to the results of the researcher-made and validated questionnaires, the level of job satisfaction of employees in the studied centers is in a relatively good condition. Although the level of job satisfaction of the studied employees was moderately high, it needs to be improved. Job satisfaction in crisis management in emergencies can be very effective and improve the performance of the organization. Thus, it is recommended to implement programs for job satisfaction and crisis management in the centers.

\section{Introduction}

uman resources are the fundamental asH sets of organizations and the source of any change and innovation in organizations [1]. The success of organizations depends on various factors, and the job satisfaction of the employees is one of the most important factors [2]. When the human resources of an organization work adequately to fulfill the assigned tasks, the desired goals can be achieved. Job satisfaction is one of the most challenging organizational concepts and the basis of many management policies to increase the productivity and efficiency of the organization. Most people spend about half of their waking hours at work. Thus, job satisfaction is of great importance [1]. One of the efforts that organizations should make to maintain human resources is to create job satisfaction in employees. Human resources are one of the most critical resources of any organization. Therefore, organizations must use their human resources effectively to achieve their goals and overcome environmental challenges [2].

Job satisfaction is part of life satisfaction. At the organizational level, neglecting job satisfaction for a long time disrupts the organizational system and causes rebellion, absenteeism, and a low sense of responsibility of employees [3]. Job satisfaction is the type of attitude and the positive tendencies or feelings people have towards their jobs and after doing the job. Job satisfaction is not a single aspect factor. It comprises a complex interaction between job tasks, responsibility, actions and reactions, motivations, and encouragement [4]. In general, different definitions have been provided for job satisfaction. For example, according to Kaliski, job satisfaction is the feeling of success and achievement of an employee at work. It leads to the recognition, receiving income, pro- motion, and achievement of other goals resulting in the sense of accomplishment [5].

The apparent effects of job satisfaction are increasing self-confidence and physical and mental health of people, doing better work, and on the other hand, improving communication and creating a very favorable organizational atmosphere, and subsequently attracting and retaining employees [6]. Also, employees with low job satisfaction have less mental health, which negatively affects the individual's private life and even society [710]. Besides, other factors, such as anxiety, absence from work, delay in doing a task, leaving the work, and early retirement are other adverse effects of job dissatisfaction [6]. Some believe that job satisfaction is related to psychological factors; in other words, these people justify job satisfaction primarily from psychological perspectives and personal characteristics and consider it a kind of emotional adaptation to the job and employment conditions. Therefore, job satisfaction is a multidimensional concept and is related to several factors. In other words, job satisfaction will be achieved by realizing a set of factors, such as the nature and conditions of work, salary, opportunities for career advancement and promotion, how to supervise, and relationships with colleagues [7]. Job stress is the opposite of job satisfaction. The higher the level of exposure to job stress in the workplace, the lower the performance and productivity of individuals $[8,9]$.

On the other hand, the crisis is an integral part of any organization, and the inherent feature of any organization is dynamism when faced with a crisis. In other words, one of the conditions for the success of any organization is to provide an appropriate response when a crisis occurs [10]. When the organizational environment manages crises well, employees feel complete mental health and are satisfied with their work, and as a result, 
their efficiency increases [11]. Thus, an organization can have the best safety and crisis management performance in preventing possible injuries caused by accidents and occupational diseases of employees when the necessary agreement and understanding has been reached among the employees to implement the work instructions. Paying attention to creating a safe environment and improving the health status of the workplace will create a suitable atmosphere in the workplace. It ultimately increases job satisfaction, which has a direct and definite effect on crisis prevention, and also, in case of unforeseen events, crisis management will be done in a more organized manner [12]. Because disasters have always put pressure on health care systems, all caregivers, including those in the rehabilitation department, must have the experience and skills needed to manage emergencies.

A well-codified training program in health systems can significantly control crises and reduce the risks involved. Therefore, the best practice in crisis management is to prevent possible injuries caused by accidents. Following the reduction of damages caused in the workplace, the level of immunity increases and the job satisfaction of employees increases, and the role of crisis management becomes more prominent [13]. Today, attention to job satisfaction in the health care sector has become more important, and rehabilitation staff, as one of the important health care staff, play an important role in promoting community health. No effective measures have been taken to investigate the job satisfaction of rehabilitation center staff and its relationship with crisis management in Tehran Province, Iran. Therefore, this study aimed to investigate the relationship between characteristics of individuals and job satisfaction with the crisis management approach. We try to draw the attention of senior staff and provincial managers of this organization to this critical and necessary issue and provide solutions to increase awareness in the field of crisis management and control of risk factors.

\section{Materials and Methods}

This study was a descriptive correlational study conducted in 2018. The study population consists of all nongovernmental rehabilitation centers under the supervision of the Tehran Welfare Organization and their staff (28 centers with 1403 employees). Sampling was done by the census method. This research is part of Poursadeghian et al. study, which has been published in the Journal of Rehabilitation [14]. The inclusion criteria included the willingness to participate in the study, work experience in at least one rehabilitation center for 2 years, full- time working in a rehabilitation center, and the exclusion criterion was the unwillingness to cooperate in the study.

Demographic information was collected using the Job Descriptive Index (JDI). JDI was standardized by Vysvky and Chrome in 1991 and contains 39 questions or items that include 5 indicators (job activity, management, group activities, reward system, and payment system). We used only the questions of the demographic section. JDI is scored based on semantic differentiation. The respondent is asked to mark a concept on a 5-point scale. The numbers on a continuum (from 1 to 5) indicate the score assigned to the concept. To measure job satisfaction, first, the scores of each dimension should be separately calculated, and then, the scores of all dimensions are summed and divided by five. The scoring system is as follows: score 1 indicates that the person has no satisfaction; score 2 indicates low satisfaction; score 3 indicates average satisfaction; score 4 indicates high satisfaction, and score 5 represents a very high level of satisfaction.

A researcher-made questionnaire was used to examine the relationship between public safety and firefighting as a criterion for crisis management and job satisfaction. Accordingly, by reviewing the sources and tools used in similar studies, a draft of the researcher-made questionnaire was prepared and designed. To check the validity and reliability of the questionnaire, we asked 5-10 personnel working in rehabilitation centers to provide their opinion regarding its content, clarification, and simplicity. The reliability of the tool was also evaluated using the Cronbach $\alpha$ coefficient. Finally, after ensuring the validity and reliability of the instrument, it was used to collect research data. To calculate the score of this questionnaire, we asked the experts' opinions about the content of the scale. They were asked to classify each question based on the 5-point Likert scale. The scoring system [1-5] was as follows: $1=$ poor management, $2=$ low management, $3=$ medium level of management, $4=$ medium to a high level of management, and 5=very high management level [15]. Finally, the data were analyzed using SPSS software v. 20, and the significance level was set at $\mathrm{P}=0.05$.

\section{Results}

Examination of the findings based on demographic variables

In this section, the differences of the respondents' views based on their demographic characteristics are examined. Demographic characteristics in this study were age, gender, level of education, work experience, and 
Table 1. Comparison of the average job satisfaction between age groups

\begin{tabular}{|c|c|c|c|c|c|}
\hline \multirow{2}{*}{ Variables } & \multicolumn{4}{|c|}{ Age Group (y) } & \multirow{2}{*}{$\mathbf{P}$} \\
\hline & $<25$ (337) & $26-35(360)$ & $36-45(370)$ & $\begin{array}{c}\text { More than } 45 \\
\text { (336) }\end{array}$ & \\
\hline Satisfaction & 3.15 & 3.11 & 3.11 & 3.09 & 0.36 \\
\hline Job & 3.41 & 3.40 & 3.41 & 3.39 & 0.98 \\
\hline Supervisor & 3.33 & 3.27 & 3.25 & 3.25 & 0.002 \\
\hline Coworker & 3.60 & 3.62 & 3.59 & 3.61 & 0.115 \\
\hline Promotion & 3.09 & 3.02 & 3.05 & 3.00 & 0.478 \\
\hline Payment & 2.30 & 2.24 & 2.23 & 2.23 & 0.752 \\
\hline
\end{tabular}

the number of working hours. Mann-Whitney U test or Kruskal-Wallis test were used where appropriate.

Differences in job satisfaction of respondents based on age

The subjects in the present study were divided into four groups in terms of age (less than 25 years, 26 to 35 years, 36 to 45 years, and more than 45 years). Therefore, the Kruskal-Wallis test was used to compare the differences in people's views based on their age. Using this test, we determined whether the job satisfaction of employees in different age groups is the same or not.

According to Table 1, the difference in the individuals' ages regarding the research variables was investigated at $95 \%$ confidence. Regarding job satisfaction and all components of job satisfaction except the supervisor, the level of significance was higher than the level of error. Therefore, there was no reason to reject the null hypothesis. Therefore, the age status of people does not affect their views. However, regarding the supervisors, it can be said that with the age of the employees, their satisfaction with them decreases.

Differences in job satisfaction of the subjects based on working hours

The present study subjects were also divided into 4 categories in terms of working hours (less than $20 \mathrm{~h}, 20$ to $40 \mathrm{~h}, 40$ to $60 \mathrm{~h}$, and more than $60 \mathrm{~h}$ ). Therefore, the Kruskal-Wallis test was used to compare the differences in their views based on work experience.

According to Table 2, the difference in job satisfaction in subjects with different working hours was investigated at a 95\% confidence level. Regarding job satisfaction and all components of job satisfaction except the supervisor, the level of significance was higher than the level of error. Therefore, there was no reason to reject the null hypothesis. And the difference in people's working hours does not affect their views. However, concerning

Table 2. Comparison of average job satisfaction in terms of working hours

\begin{tabular}{|c|c|c|c|c|}
\hline \multirow{2}{*}{ Variables } & \multicolumn{3}{|c|}{ Working Hours } & \multirow{2}{*}{$\mathbf{P}$} \\
\hline & Less than 20 (162) & $21-40$ (719) & More than 40 (522) & \\
\hline Satisfaction & 3.14 & 3.11 & 3.12 & 0.106 \\
\hline Job & 3.41 & 3.40 & 3.40 & 0.919 \\
\hline Supervisor & 3.33 & 3.28 & 3.26 & 0.021 \\
\hline Coworker & 3.61 & 3.60 & 3.61 & 0.258 \\
\hline Promotion & 3.09 & 3.02 & 3.06 & 0.350 \\
\hline Payment & 2.29 & 2.23 & 2.26 & 0.645 \\
\hline
\end{tabular}


Table 3. Comparison of average job satisfaction between educational levels

\begin{tabular}{cccccc}
\hline \multirow{2}{*}{ Variables } & \multicolumn{5}{c}{ Educational Levels } \\
\cline { 2 - 5 } & $\begin{array}{c}\text { Diploma and } \\
\text { below (439) }\end{array}$ & $\begin{array}{c}\text { Associate degree } \\
\mathbf{( 3 3 8 )}\end{array}$ & $\begin{array}{c}\text { Bachelor's degree } \\
\mathbf{( 5 0 4 )}\end{array}$ & $\begin{array}{c}\text { Master's degree } \\
\text { and above (122) }\end{array}$ & P \\
\hline Job satisfaction & 3.09 & 3.15 & 3.13 & 3.06 & 0.004 \\
Job & 3.39 & 3.41 & 3.42 & 3.37 & 0.101 \\
\hline Supervisor & 3.24 & 3.30 & 3.31 & 3.22 & 0.016 \\
Coworker & 3.61 & 3.59 & 3.62 & 3.61 & 0.131 \\
\hline Promotion & 3.01 & 3.12 & 3.04 & 2.29 & 0.041 \\
\hline Payment & 2.21 & 2.31 & 2.27 & 2.16 & 0.092 \\
\hline
\end{tabular}

supervisor, it can be said that with the higher age of employees, their satisfaction with supervisors decreases.

Differences in job satisfaction of the subjects based on education

The subjects in the present study were also divided into five categories in terms of educational level (diploma and below, Associate degree, Bachelor's degree, Master's degree, and higher). Therefore, the Kruskal-Wallis test was used to compare the differences in job satisfaction based on their educational level.

According to Table 3, the difference in job satisfaction in subjects with different educational levels was investigated at a 95\% confidence level. Regarding job satisfaction, as well as supervisor and promotion, the significance level was less than the level of error. Therefore, it can be argued that job satisfaction, satisfaction with the supervisor, and satisfaction with promotion had a signifi- cant difference between educational levels. In general, with increasing the level of education, people's satisfaction also decreases.

Differences of subjects' views based on work experience

The subjects in the present study were divided into three categories in terms of work experience. Therefore, the Kruskal-Wallis test was used to compare the differences of views based on work experience.

According to Table 4, the difference in job satisfaction in subjects with different work experiences was investigated at a $95 \%$ confidence level. Regarding job satisfaction and all of its components except the supervisor, the level of significance was higher than the level of error. Therefore, there was no reason to reject the null hypothesis. Therefore, the difference in people's working hours does not affect their views. However, concerning supervisor, it can

Table 4. Comparing the average job satisfaction between cases with different work experiences

\begin{tabular}{|c|c|c|c|c|}
\hline \multirow{2}{*}{ Variables } & \multicolumn{3}{|c|}{ Work Experience (y) } & \multirow{2}{*}{$\mathbf{P}$} \\
\hline & Less than 5 (520) & $6-10(527)$ & over 10 (356) & \\
\hline Satisfaction & 3.13 & 3.12 & 3.09 & 0.087 \\
\hline Job & 3.41 & 3.41 & 3.39 & 0.997 \\
\hline Supervisor & 3.31 & 3.27 & 3.24 & 0.011 \\
\hline Coworker & 3.60 & 3.61 & 3.61 & 0.803 \\
\hline Promotion & 3.07 & 3.06 & 2.98 & 0.177 \\
\hline Payment & 2.27 & 2.26 & 2.21 & 0.690 \\
\hline
\end{tabular}


Table 5. Comparison of average job satisfaction between women and men

\begin{tabular}{|c|c|c|c|c|c|}
\hline \multirow{2}{*}{ Variables } & \multirow{2}{*}{ Gender } & \multirow{2}{*}{ No. } & \multirow{2}{*}{ Mean } & \multicolumn{2}{|c|}{$\mathbf{P}$} \\
\hline & & & & t & $\mathbf{P}$ \\
\hline \multirow{3}{*}{ Satisfaction } & Female & 746 & 3.09 & \multirow{3}{*}{-4.76} & \multirow{3}{*}{$<0.001$} \\
\hline & & & & & \\
\hline & Male & 657 & 3.15 & & \\
\hline \multirow{3}{*}{ Job } & Female & 746 & 3.38 & \multirow{3}{*}{-3.73} & \multirow{3}{*}{$<0.001$} \\
\hline & & & & & \\
\hline & Male & 657 & 3.43 & & \\
\hline \multirow{3}{*}{ Supervisor } & Female & 746 & 3.26 & \multirow{3}{*}{-1.63} & \multirow{3}{*}{0.014} \\
\hline & & & & & \\
\hline & Male & 657 & 3.29 & & \\
\hline \multirow{3}{*}{ Coworker } & Female & 746 & 3.59 & \multirow{3}{*}{-2.46} & \multirow{3}{*}{0.014} \\
\hline & & & & & \\
\hline & Male & 657 & 3.62 & & \\
\hline \multirow{3}{*}{ Promotion } & Female & 746 & 3.00 & \multirow{3}{*}{-2.57} & \multirow{3}{*}{0.010} \\
\hline & & & & & \\
\hline & Male & 657 & 3.09 & & \\
\hline \multirow{3}{*}{ Payment } & Female & 746 & 2.19 & \multirow{3}{*}{-4.48} & \multirow{3}{*}{$<0.001$} \\
\hline & & & & & \\
\hline & Male & 657 & 2.32 & & \\
\hline
\end{tabular}

be said that with the increase of employees' work experience, their satisfaction with their supervisors decreases.

The mean difference of the respondents based on gender

The Mann-Whitney U test was used to compare differences of views based on gender. According to Table 5, the differences between the views of men and women in terms of each research variable were investigated at a $95 \%$ confidence level. Accordingly, men and women had different views regarding all variables, except for the supervisor, so that the mean value obtained from men was higher than that of women.

\section{General safety}

To evaluate the general safety level, we used the 1-sample Wilcoxon test due to the lack of normal distribution of the data. The result of the Wilcoxon test showed that at the error level of $5 \%$, the mean of the general safety score of employees was significantly different from the hypothetical mean value. As a result, the general safety score of the employees was about 0.57 more than the hypothetical value. It can also be seen in the chart below

Table 6. The mean values for the public safety

\begin{tabular}{cccccccc}
\hline Variable & $\begin{array}{c}\text { Hypothetical } \\
\text { Mean (median) }\end{array}$ & Observed Mean & Observed Median & Value Criterion & Min. & Max. & P \\
\hline General safety & 3 & 3.54 & 3.57 & 28.63 & 1.57 & 5 & $<0.001$ \\
\hline & & & & $\begin{array}{c}\text { |llealth in } \\
\text { Emergencies and D]isasters [Oluarterly }\end{array}$ \\
\hline
\end{tabular}

Table 7. The mean values for the fire extinguishing

\begin{tabular}{cccccccc}
\hline Variable & $\begin{array}{c}\text { Hypothetical } \\
\text { Mean (median) }\end{array}$ & Observed Mean & Observed Median & Value Criterion & Min. & Max. & P \\
\hline Fire extinguishing & 3 & 3.63 & 3.6 & 31.89 & 2.54 & 4.75 & $<0.001$ \\
\hline & & & & $\begin{array}{c}\text { lilealth hin } \\
\text { Emergencies and (D)isasters (Oluarterly }\end{array}$ \\
\hline
\end{tabular}




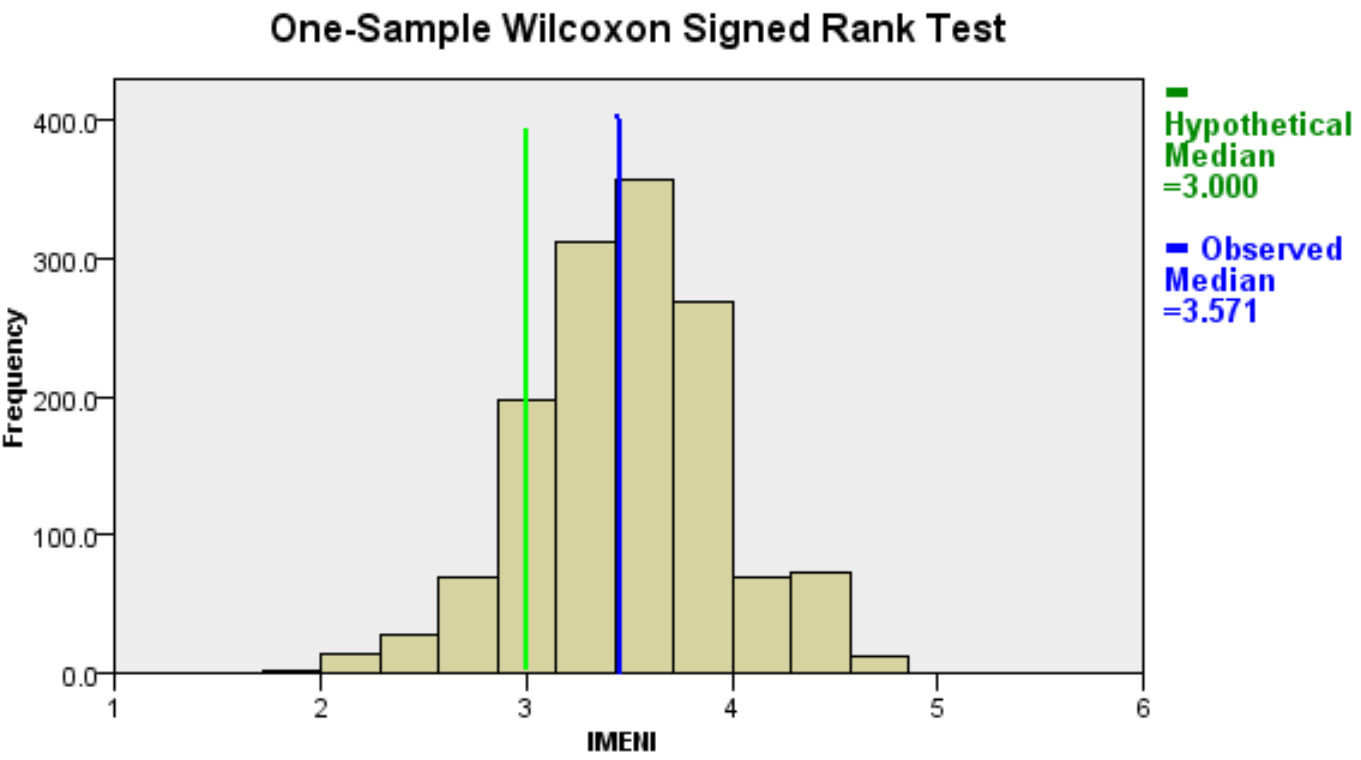

IMEIII

Figure 1. Comparison of the hypothetical scores and observed scores of fire extinguishing

Figure 1 shows a comparison of the hypothetical scores and observed scores for the general safety of the employees.

Fire extinguishing

To evaluate the status of the fire extinguishing, we used the 1-sample Wilcoxon test due to the lack of normal distribution of the data. The result of the Wilcoxon test showed that at the error level of $5 \%$, the average score of fire extinguishing was significantly different from the hypothetical average score so that the fire extinguishing score of employees was about 0.60 more than the hypothetical value (Figure 2).

\section{Discussion}

This study aimed to investigate job satisfaction among employees of rehabilitation centers in Tehran Province. They consist of 746 women and 657 men. The age group of 36 to 45 years had the highest frequency, and the lowest frequency was related to the age group above 45 years, followed by the age group less than 25 years. Regarding education, those with a Master's degree and above showed the lowest frequency, and those with a Bachelor's degree showed the highest frequency. The results also showed that the range of work experience was between 1 to 15 years. The average job satisfaction of the employees was 3.12, which was at a moderate level and was in line with the study by Afshar et al. [16] and

\section{One-Sample Wilcoxon Signed Rank Test}

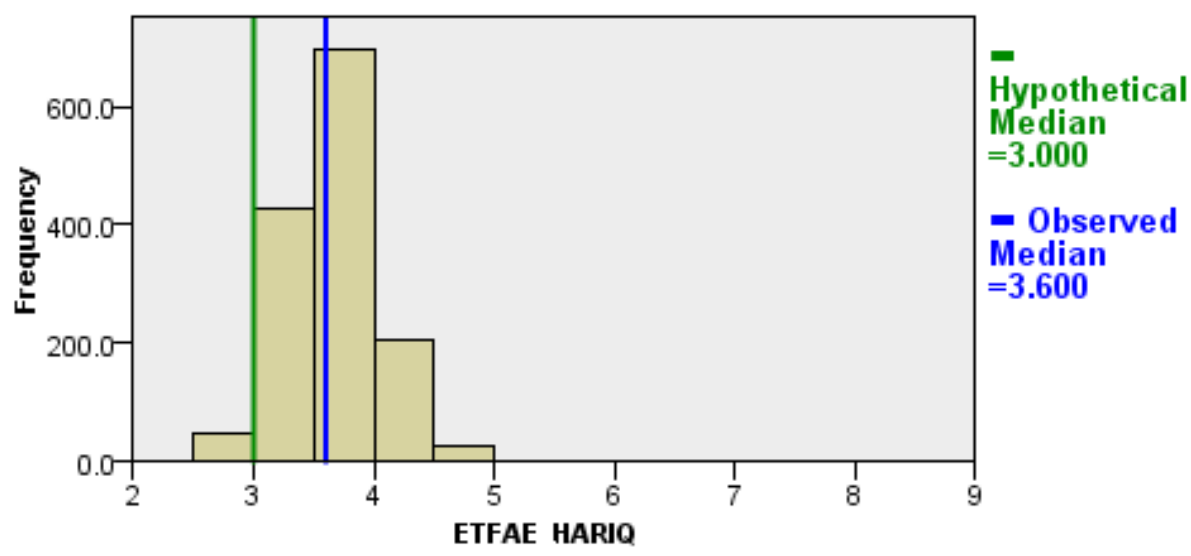

Figure 2. Comparison of the accessible score and the observed score of the firefighters 
Table 8. Relationship between crisis management variables and job satisfaction

\begin{tabular}{|c|c|}
\hline Relationship Between Variables & Correlation \\
\hline Public safety with job satisfaction & 0.227 \\
\hline Firefighting with job satisfaction & 0.215 \\
\hline
\end{tabular}

Mastane et al. [17]. The results of the study showed that among the job satisfaction variables, a coworker (average 3.61) has the highest, and the payment (average 2.25) has the lowest average. In Afshari et al. study, there was no significant relationship between demographic variables and motivational potential and job satisfaction [16].

In Mastane et al. study, there was no significant relationship between job satisfaction and demographic factors, including age, work experience, gender, marital status, and work shift [17]. Also, in Fooladvandi et al. study, there was no relationship between demographic variables (age, education, experience, organization, and gender) with job satisfaction and its dimensions [18].

There are controversial results regarding gender and level of job satisfaction. For example, in Mousavi Tabar study [19], a significant relationship was reported between job satisfaction and gender, so that women's job satisfaction was higher than men's. In Musazadeh et al. study on the ICU staff, the results showed that job satisfaction in women was higher than in men [20]. However, in the present study, the results showed that men's job satisfaction is higher than women's, which can be due to the studied population and cultural differences in different cities. According to Tables 6, 7, and 8 general safety and fire extinguishing, which were selected as two indicators of crisis management in this study, had an average higher than the middle of the Likert scale. The higher the average, the more appropriate these variables are. In other words, the higher the average, the better the crisis management situation, which was in line with the results of the study of Goodarzi et al. [21]. Jafari et al. examined the relationship between safety status and job satisfaction of nurses. They indicated that the higher the crisis management conditions at the hospital level, such as fire safety and emergency safety in the workplace, the more satisfied nurses would be in their work environment, indicating the importance of crisis management [22].

The present study examined the level of job satisfaction of rehabilitation staff. The results showed no significant relationship between the demographic information of individuals and their level of job satisfaction. Therefore, to increase job satisfaction, it is recommended to apply effective management measures to optimize the assessment of safety and health performance regarding crisis management and reduce risk in rehabilitation centers and other similar organizations. Also, to improve safety and health conditions, it is recommended to establish safety and health management systems in rehabilitation centers and provide the necessary training to the staff in this field by holding crisis management training workshops.

\section{Ethical Considerations}

\section{Compliance with ethical guidelines}

This article was taken from a study (1688) approved by the Research Council of the University of Social Welfare and Rehabilitation Sciences. The research protocol and ethical issues according to 31 codes of ethics in the research were approved by the University of Social Welfare and Rehabilitation Sciences (Code: IR.USWR. REC.1396.359).

\section{Funding}

This study was supported by University of Social Welfare and Rehabilitation Sciences (Grant No.: 1688).

\section{Authors' contributions}

All authors equally contributed to preparing this article.

\section{Conflict of interest}

The authors declared no conflict of interest.

\section{Acknowledgments}

The authors would like to thank the University of Social Welfare and Rehabilitation Sciences and also the staff of non-governmental Rehabilitation Centers in Tehran. 


\section{References}

[1] Kim SY, Fernandez S. Employee empowerment and turnover intention in the US federal bureaucracy. The American Review of Public Administration. 2017; 47(1):4-22. [DOI:10.1177/0275074015583712]

[2] Rezapour Y, Rezai H, Hosseini SA, Mohseni Takalu MT. The role of faith in work, religious beliefs, and spirituality in the prediction of job satisfaction among rehabilitation experts. Iranian Rehabilitation Journal. 2016; 14(4):217-22. [DOI: 10.18869/nrip.irj.14.4.217]

[3] Movahhed MA, Moghaddam YH. [Survey of job satisfaction and the factors affecting it, with employed nurses in the educational and curative centers of Uromieh university of medical sciences, 1380 (Persian)]. Nursing And Midwifery Journal. 2004; 2(2). http:/ / unmf.umsu.ac.ir/article-1-150-en.html

[4] Karami J, Moradi A, Hatamian P. [The effect of resilience, self-efficacy, and social support on job satisfaction among the employed, middle-aged and elderly (Persian)]. Salmand: Iranian Journal of Ageing. 2017 Dec 10;12(3):300-11. [DOI:10.21859/sija.12.3.300]

[5] Kaliski BS. Encyclopedia of business and finance. New York: Macmillan Reference USA; 2001. https:/ / books.google. com/books/about/Encyclopedia_of_business_and_finance. $\mathrm{html}$ ?id=1lcRAQAAMAAJ

[6] Mohammadkhani P. [Sources of occupational stress in employees of rehabilitation organization and effect of these stressors on their job satisfaction (Persian)]. Archives of Rehabilitation. 2000; 1(1):50-7. http:/ / rehabilitationj.uswr.ac.ir/ article-1-509-en.html

[7] Ebrahimi Barmi B, Hosseini M, Abdi K, Bakhshi E. [The relationship of spiritual intelligence and rehabilitation staff's perceived stress in welfare organizations centers in Tehran and shemiranat: 2017 (Persian)]. Archives of Rehabilitation. 2018; 19(3):228-37. [DOI:10.32598/rj.19.3.228]

[8] Abbasi M, Yazdanirad S, Habibi P, Arabi S, Fallah Madvari $\mathrm{R}$, Mehri A, et al. Relationship among noise exposure, sensitivity, and noise annoyance with job satisfaction and job stress in a textile industry. Noise \& Vibration Worldwide. 2019; 50(6):195-201. [DOI:10.1177/0957456519853812]

[9] Poursadeghiyan M, Abbasi M, Mehri A, Hami M, Raei M, Ebrahimi MH. Relationship between job stress and anxiety, depression and job satisfaction in nurses in Iran. The social sciences. 2016; 11(9):2349-55. https://acgih.ir/wp-content/ uploads/2018/09/989.pdf

[10] Imani H, Gholipour A, Azar A, Pourezzat AA. [Identifying components of staffing system to develop administrative integrity (Persian)]. Journal of Public Administration. 2019; 11(2):251-84. [DOI:10.22059/jipa.2019.277466.2504]

[11] Kavoosi M, Naser Esfahane A, Rashide MM. [Explaining the Influence of Managers' individuality on their management styles in the crisis management process through presenting an applied model (case study: Managers and expers of Khuzestan crisis management headquarters) (Persian)]. Disaster Prevention and Management Knowledge (quarterly). 2019; 9(1):90-109. http://dpmk.ir/article-1-249-en.html

[12] Khammar A, Poursadeghiyan M, Marioryad H, Nabi Amjad R, Alimohammadi M, Khandan M. Patient safety climate and its affecting factors among rehabilitation health care staff of hos- pitals and rehabilitation centers in Iran-Tehran. Iranian Rehabilitation Journal. 2019; 17(1):39-48. [DOI:10.32598/irj.17.1.39]

[13] Senobari M, Havakhor N. [Evaluation of nurses' educational needs assessment in crisis nursing management in the educational and medical centers affiliated to Ahvaz Jundishapur university of medical sciences based on jennings model (Persian)]. Educational Development of Judishapur. 2020; 11(suppl):154-66. [DOI:10.22118/edc.2020.217796.1260]

[14] Poursadeqiyan M, Hosseini Foladi S, Khammar A, Amjad RN, Marioryad H, Hosseini Ghosheh SN, et al. [A survey on the relationship between the status of occupational health management and job satisfaction among staff of rehabilitation Centers in Tehran: A cross-sectional study (Persian)]. Archives of Rehabilitation. 2019; 20(3):242-55. [DOI:10.32598/rj.20.3.242]

[15] Khaleghi S, Sadeghimoghadam A, Moradi Y, Jafarizadeh $\mathrm{H}$, Ghalavand M, Poursadeqiyan M, et al. Is Nurses' Job Satisfaction Related To Occupational Health And Safety Management? Iranian Journal of Public Health (IJPH). 2021, 50(X):X.

[16] Afshar S, Mombeyni NN, Hamedi D, Karan SM, Dinari K, Nazarian M. [Job satisfaction and its correlation with motivational power score among occupational therapists in Ahvaz city (Persian)]. Scientific Journal of Rehabilitation Medicine. 2017; 6(1):143-52. [DOI:10.22037/JRM.2017.1100286]

[17] Mastane Z, Moseli 1, Zamani M, Boroumand E, Dadipour $\mathrm{S}$, Beyzaee F, et al. [Study of job satisfaction of nurses in teaching hospitals of Hormozgan university of medical sciences (Persian)]. Medical Journal of Hormozgan University. 2014; 18(3):283-9. https://www.sid.ir/en/Journal/ViewPaper. aspx?ID $=406007$

[18] Foladvandi M, Sadeghi H, Tofighi M, Asadabadi A. [Relationship between job satisfaction and emotional intelligence in critical and emergency nurses (Persian)]. Journal of Sabzevar University of Medical Sciences. 2017; 24(1):1-8. https:/ / www. sid.ir/en/journal/ViewPaper.aspx?id=542136

[19] Moosavi TS, Rahmani R, Sirati NM, Abbas ZZ. [Influence factors in job satisfaction of nurses in the selected military and civil hospital in Tehran (Persian)]. Journal of Nurse and Physician Within War. 2013; (23-24):34-9. https:/ / npwjm.ajaums. ac.ir $/$ browse.php?a_id=87\&sid=1\&slc_lang=fa

[20] Mousazadeh S, Yektatalab S, Momennasab M, Parvizy $\mathrm{S}$. Job satisfaction and related factors among Iranian intensive care unit nurses. BMC Research Notes. 2018; 11:823. [DOI:10.1186/s13104-018-3913-5]

[21] Ghoudarzi H, Vameghi R, Hosseini Fouladi S, Khammar A, Poursadeqiyan M, Kavari SH. Relationship between health and safety management status and job satisfaction among employees of rehabilitation centers with crisis management approach in kohgiluyeh and boyer-ahmad province. Health in Emergencies and Disasters. 2019; 4(4):193-200. [DOI:10.32598/hdq.4.4.193]

[22] Jafari M. [The relationship between job satisfaction and occupational safety and occupational health status of nurses in a hospital (Persian)]. Journal of Health and Safety at Work. 2012; 2(3):41-8. https://www.sid.ir/en/journal/ViewPaper. aspx?id $=560458$ 
This Page Intentionally Left Blank 